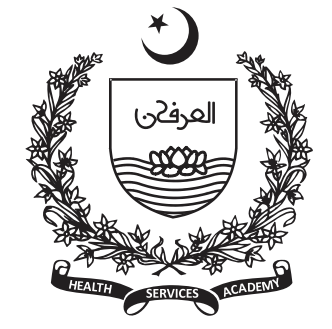

University of New South Wales

Corresponding Author: Muhammad Naveed Noor Email: naveedn.noor@gmail.com

\section{The Need for an Integrated Approach to Reducing Young People's Risk of Homelessness and HIV in Pakistan}

\author{
Muhammad Naveed Noor
}

\begin{abstract}
Background: Past research demonstrated a link between homelessness and the increased risk of HIV and other sexually transmitted infections (STIs). However, ways to reduce young people's risk of homelessness and sexual health risks have not been adequately addressed. This paper, based on the first detailed sociological exploration into the lived experiences of homeless young people, argues for the adoption of a holistic and integrated approach to health promotion that goes beyond the health sector.
\end{abstract}

Methods: In-depth interviews were conducted with twenty-nine homeless young people, aged 16-25-year-old, from Rawalpindi, Pakistan.

Results: A combination of socio-structural and interpersonal forces shaped participants' pathways to homelessness and their experiences of street life notably regarding sex work - and produce contexts of competing risks where HIV/STIs prevention became a secondary concern. Participants had a reasonable knowledge regarding nature, transmission, prevention, and to some extent, treatment of HIV/STIs. Nevertheless, this knowledge did not help them much, as most of the participants used condoms inconsistently with clients and intimate partners. Financial considerations, fear of violence from clients, and social obligations in intimate partnerships contributed to participants inconsistent condom use, increasing their risk of HIV/STIs.

Conclusion: The results indicate the importance of the Ottawa Charter of health promotion, which suggests that conventional health promotion approaches are potentially suboptimal in shaping health behaviours supportive of good health. Notably, building healthy public policies, creating supportive environments, strengthening community actions, developing personal skills, and reorienting health services can help to improve young people's socioeconomic status, which is inextricably linked with sexual health behaviour and status.

Keywords: Homelessness; HIV, sexually transmitted infections; youth

\section{Introduction}

$\mathrm{T}$ he first case of HIV in Pakistan was reported in 1987 and since then the epidemic has steadily expanded (1). In the last decade, new HIV cases have decreased by $0.7 \%$ per annum globally (2). However, according to UNAIDS (3), the number of HIV cases in Pakistan has increased at an alarming rate of $9.1 \%$ per annum from 2005 to 2015 . Since the 1980s homelessness has emerged as a critical social 
issue contributing to the increased prevalence of HIV (4). Studies from Pakistan indicate how to obtain things like money, shelter, food, and sometimes drugs, homeless young people engage in sex work, often practised unprotected $(5,6)$. These studies have generally suggested that increasing young people's knowledge about sexual health risks and safety may help them to prevent HIV/STIs. However, social research suggests that knowledge about sexual health risks and safety may not entirely help individuals to practise safer sex and structural factors like poverty, patriarchy, and heteronormativity may neutralise this knowledge (7). The present study, therefore, takes a social scientific approach to exploring the lived experiences of homeless young people who engage in sex work. Based on the findings, the paper then proposes ways to reduce their risk of homelessness and HIV/STIs.

\section{Methodology}

Structured interviews were conducted with twentynine homeless young people (16-25 years old) from Rawalpindi, Pakistan. A local non-governmental organisation (NGO) helped with the recruitment of the research participants. Sexually active young people (aged 16-25 years old) who were homeless were considered eligible to participate in the study. The interview guide comprised of three main sections: participants' reasons behind homelessness, their street-based practices, and their sexual behaviour. Thematic analysis was performed, as it permitted to identify emergent themes (8). Key ethical guidelines concerning voluntary participation, informed consent, compensation for time and expenses, and maintaining participants' confidentiality, were observed throughout the research process.

\section{Results}

The sample comprised twenty-nine participants including sixteen men, six women, and seven transgender women. Participants' mean education level was 5.8 years of schooling, but some participants $(n=6)$ did not receive a formal education. Almost all of the participants reported leaving family homes one year before the interviews took place, while a few participants $(n=3)$ became homeless more recently. The majority of the participants reported being precariously homed, while only one participant experienced rough sleeping. Most of those who were precariously homed talked about how peers provided them with accommodation. Nevertheless, a few participants secured temporary accommodation at extended family members' homes. Most $(n=23)$ of the participants engaged in dancing and/or sex work, while a few of them did jobs like rickshaw driving, house painting, scavenging, and labouring for income generation.

\section{Homelessness, sex work, and the risk of HIV/STIs}

The analysis suggests that participants' sexual risktaking was influenced by structural problems like poverty and gender inequality and how these issues shaped social interaction at an interpersonal level. For instance, a majority of participants who belonged to rural regions described how due to poverty, parents expected them to leave schools and find paid work to earn money and support their families. Participants, due to limited work opportunities in the rural regions, moved to Rawalpindi (one of the big urban centres in the country), so that they could engage in paid work:

I left my home to find work because we are poor people. Back in my village, there is no work; there are some jobs that I could do there, but I count not earn much. Here in Rawalpindi, wages are comparatively better (Imran, 19).

Also, violence against women and sexually/gender diverse participants (notably gay men and transgender women), and in a few cases, illicit drug use, were reported as the main reasons for leaving home:

My family know who I am. I am a moorat [transgender] and I feel happy with transgender people. They had beaten me up and even shaved my head, but still, I said I had to meet them. Then they kicked me out of the home (Yasira, 17).

Since participants' lives were characterised by the lack of family support, they looked for other options of support outside their family homes. Here, existing relationships on the streets helped participants in connecting them to peer groups, which further gave them access to financial and social resources (i.e. the sense of belonging and social support):

We live in a form of a group and we all are friends. All of my group members are of my community and we avoid meeting people outside our circle. Living in a group ensures our protection, otherwise we cannot survive (Washma, 22).

The streets-life further determined how participants would be positioned within the broader society. A study based on the same qualitative data showed how participants engaged in concurrent sexual 
partnerships and used condoms inconsistently, indicating that they were on the risk of HIV (9). For example, for most of the participants, the financial gains were dependent on sex work, which is usually attributed to the professions of social outcasts in Pakistan:

I tried to find some job but could not secure one. Therefore, I started to do sex work, and now this is my source of income, but if I can secure some job, I will quit doing sex work (Rashid, 22).

In addition to practising sex work, participants established long-term intimate relationships - and obtained various resources from them. Most participants appeared to have good knowledge of HIV/STIs. However, they used condoms inconsistently with intimate partners and clients due to trust within intimate partnerships, risk of violence from clients, and due to a desire to earn more money from sex work. While participants used alternatives like withdrawal and oral sex to protect themselves, these strategies were not always useful and might even be harmful.

In sum, social structural issues like poverty and gender inequality contributed not only to participants' homelessness but also to their decision to practice sex work on the streets. Social obligations in intimate relationships, money, and risk of violence led participants to engage in sexual risk-taking.

\section{Discussion}

The results show that a range of macro- and microlevel forces contributed to participants' homelessness, a situation which encapsulates various risks: socioeconomic disadvantage, discrimination, and substandard living conditions, all of which led to the high-risk decisions that participants made. This indicates the need for an "integrated approach" (10) to health promotion, which should go beyond the health sector. An integrated approach recommends that the health and non-health sectors in Pakistan should take coordinated action to improve young people's social and financial status and support good health. The best approaches to addressing complex, socially-produced health problems can be guided by the 'five action areas' outlined in the Ottawa Charter for Health Promotion, including building healthy public policy, creating a supportive environment, strengthening community action, developing personal skills, and reorienting health services towards primary health care (11).
Building healthy public policy implies that policymakers should work together to promote legislation, fiscal measures, and organisational change that can contribute to the improved health of individuals. As the results show a link between homelessness and risky sexual behaviour, it is important to consider why young people become homeless in the first place. Especially, the relationship between poverty and homelessness signals the need for actions taken to reduce poverty in Pakistan. Although efforts have been made to address poverty through microfinance and charity programs, the scale of their success is limited (12). A reconsideration of policies that underpin the existing microfinance programs may help to achieve better outcomes. Adopting principles of a more successful microfinance program, like the Grameen Bank in Bangladesh, may help to achieve better results in poverty alleviation (13).

There is also a need to promote mainstream as well as technical/vocational education among young people. Since Pakistan is constitutionally committed to providing free education up to Grade 10, students can receive free education in public schools (14). But, poor parents often expect children to work to provide them with some financial support, which can lead to their discontinuation of education (15). Waseela-e-Taleem (WeT), a cash transfer program, has already been helping parents to ensure their children's attendance $70 \%$ to receive PKR 250/month. The program has only been partially successful, as thousands of children of eligible households remained out of school (16). Perhaps aligning the WeT program's policies with more successful cash transfer programs in other developing countries may help to achieve better outcomes. $(17,18)$. For example, increasing the amount of cash transfer to students can allow parents to ensure children's attendance at school.

The study also demonstrates how negative attitudes towards young people with diverse gender and sexual identities contributed to their homelessness. While it is a complex challenge to address this issue in a conservative society like Pakistan, political and legal authorities may promote and strengthen laws and institutional policies to safeguard their rights. Several laws are already in place to protect women and transgender people, yet they still face discrimination and violence for various reasons including a lack of awareness of laws and rights among the general public as well as women and transgender people, 
discriminatory practices by the police and an inefficient lower judiciary.

The relationship between individuals and their physical and social environments can shape their behaviour, which has implications for good or bad health. Creating environments that can enable individuals to take control of the social determinants of their health can promote good health. In the present study, a combination of factors formed an environment less conducive of participants protecting against sexual health risks. Therefore, NGOs that are already working with homeless young people might also consider providing sexual health education to their intimate partners (who may or may not be homeless) and clients. Specifically, this could help intimate partners to consider achieving good health as a mutual responsibility, which could increase their condom use.

Empowering communities through building their capacity can enable individuals to take specific actions supportive of good health (11). The study results show how the rejection of participants' fundamental rights to receive education, enter the formal job market, and be accepted as a person with a diverse sexual or gender identity has systematically put them at risk of HIV. Putting homelessness and HIV on the agenda of civil society organisations can help to address the needs of young people.

Peer education interventions, in which peers educate homeless young people on sexual health issues, can help to increase their awareness of HIV transmission, prevention, and treatment. Globally, peer education has achieved promising outcomes in health promotion among marginalised population groups $(19,20)$. In India, the Sonagachi Project has successfully reduced HIV transmission among female sex workers by providing them with sexual health education, medical care, financial incentives, and protection by the police (21). NGOs in Pakistan could review the focus adopted by the Sonagachi Project while designing the intervention for homeless young people. NGOs might also need to consider linking homeless young people with technical/vocational institutes that operate in almost all districts of Pakistan and offer short courses related to beautification, dress designing and making, information technology, office management, and other technical and mechanical skills.

Participants largely received sexual health education and medical care from a few NGOs with limited resources and infrastructure, rather than from the government health services. Pakistan is one of the initial signatories of the WHO Alma-Ata Declaration and, hence, is committed to promoting health among its citizens (22). However, child immunization, family planning, and maternal health promotion programs have largely been the focus of health promotion in the country. Since 1994, the Lady Health Worker Program (LHWP) has contributed to improved contraceptive use and maternal and child health in Pakistan (23). Nevertheless, few efforts have been made to promote sexual health in the country (24). The government might consider also deploying male health workers and connect them and the lady health workers with the National AIDS Control Program (NACP) to prevent HIV among homeless young people and their counterparts.

\section{Conclusion}

This paper has illuminated social processes that can put young people at an increased risk of HIV/STIs in the context of Pakistan. The study's exposition of risky sexual practices of homeless young people is a reminder that HIV/STIs should not be reduced to the context of a brothel- or home-based sex work; rather, it is necessary to understand the social conditions shaping individuals' sexual practices that can place them at increased risk of HIV/STIs. Therefore, the conventional approach of promoting health through raising awareness regarding sexual health risks may continue to bring less than promising outcomes, unless we focus on how poverty, heteronormativity, and patriarchy operate to increase the chances of risky sex and HIV. The fact that young people in the present study displayed agency within significant social structural constraints reflect their resilience and efforts to improve their social and financial status. Together, policymakers, academics, and civil society organizations can help young people utilise their abilities in productive ways to further contribute to the socioeconomic development of Pakistan, a country where young people make up over half of the population.

\section{Disclosure statement}

I have no conflicts of interest to declare. 


\section{References}

1. Khan AH, Khan A. The HIV epidemic in Pakistan. Journal of Pakistan Medical Association. 2010;60(4).

2. Waheed U, Satti HS, Arshad M, Rauf A. Epidemiology of HIV/AIDS and Syphilis among high risk groups in Pakistan. Pakistan Journal of Zoology. 2017;49(5):1834.

3. UNAIDS. Country factsheets, Pakistan2017. Available from:

www.unaids.org/en/regionscountries/countries/pakis $\tan$.

4. Nyamathi A, Vasquez R. Impact of poverty, homelessness, and drugs on Hispanic women at risk of HIV infection. Hispanic Journal of Behavioral Sciences. 1989;11(4):299-314.

5. Towe VL, ul Hasan S, Zafar ST, Sherman SG. Street life and drug risk behaviors associated with exchanging sex among male street children in Lahore, Pakistan. Journal of Adolescent Health. 2009;44(3):222-8.

6. Emmanuel F, Iqbal F, Khan N. Street children in Pakistan: a group at risk of HIV/ AIDS. Pakistan; 2005.

7. Kippax S, Stephenson N, Parker RG, Aggleton P. Between individual agency and structure in HIV prevention: understanding the middle ground of social practice. American journal of public health. 2013;103(8):1367-75.

8. Braun V, Clarke V. Using thematic analysis in psychology. Qualitative research in psychology. 2006;3(2):77-101.

9. Noor MN, Holt M, Qureshi A, de Wit J, Bryant J. Sexual risk-taking among homeless young people in Pakistan. Health \& Social Care in the Community.

10. Keleher H. Health promotion principles. In: Keleher H, MacDougall HC, Murphy B, editors. Understanding Health Promotion. Melbourne: Oxford University Press; 2008.

11. WHO. The Ottawa Charter for Health Promotion. 1986.

12. Ashraf MA. Poverty and Its Alleviation: The Case of Pakistan. In: Staicu GL, editor. Poverty, Inequality and Policy2017.

13. Yunus M. Grameen bank, microcredit, and Millennium Development Goals. Economic and Political Weekly. 2004;39(36):4077-80.

14. National Education Policy Framework. National Education Policy Framework2018. Available from:
http://aserpakistan.org/document/2018/National_Ed uctaion_Policy_Framework_2018_Final.pdf.

15. Hazarika G, Bedi A. Schooling Costs and Child Work in Rural Pakistan. The Journal of Development Studies. 2003;39(5):29-64.

16. Cheema I, Asia MG, Hunt S, Javeed S, Lone T, O'Leary $\mathrm{S}$. Benazir Income Support Programme Evaluation of the Waseela-e-Taleem Conditional Cash Transfer. Islamabad; 2016.

17. Barrera-Osorio F, Bertrand M, Linden LL, Perez-Calle F. Improving the design of conditional transfer programs: Evidence from a randomized education experiment in Colombia. American Economic Journal: Applied Economics. 2011;3(2):167-95.

18. MacPhail C, Khoza N, Selin A, Julien A, Twine R, Wagner RG, et al. Cash transfer for HIV prevention: What do young women spend it on? Mixed methods findings from HPTN 068. BMC Public Health. 2018;18(10).

19. Sun WH, Miu HY, Wong CK, Tucker JD, Wong WC. Assessing participation and effectiveness of the peer-led approach in youth sexual health education: Systematic review and meta-analysis in more developed countries. The Journal of Sex Research. 2018;15(1):31-44.

20. Shah P, Kibel M, Ayuku D, Lobun R, Ayieko J, Keter A, et al. A pilot study of "peer navigators" to promote uptake of HIV testing, care, and treatment among streetconnected children and youth in Eldoret, Kenya. AIDS and Behavior. 2018;23(4):908-19.

21. Cornish F, Campbell C. The social conditions for successful peer education: A comparison of two HIV prevention programs run by sex workers in India and South Africa. American Journal of Community Psychology. 2009;44:123-35.

22. Ronis KA, Nishtar S. Community health promotion in Pakistan: A policy development perspective. Promotion \& Education. 2007;14(2):98-9.

23. Zhu N, Allen E, Kearns A, Caglia J, Atun R. Lady health workers in Pakistan, Improving access to health care for rural women and families. 2014.

24. Talpur AA, Khowaja AR. Awareness and attitude towards sex health education and sexual health services among youngsters in rural and urban settings of Sindh, Pakistan. Journal of Pakistan Medical Association. 2012;62(7):708-12. 